Check for updates

Cite this: RSC Adv., 2018, 8, 19381

Received 1st April 2018

Accepted 10th May 2018

DOI: $10.1039 / c 8 r a 02813 c$

rsc.li/rsc-advances

\section{Highly sensitive sensing of hydroquinone and catechol based on $\beta$-cyclodextrin-modified carbon dots $†$}

\author{
Zhong-Yi Lin, ${ }^{a}$ Yuan-Chieh Kuo, ${ }^{a}$ Chih-Jui Chang, ${ }^{c}$ Yu-Syuan Lin, ${ }^{a}$ Tai-Chia Chiu (D) ab \\ and Cho-Chun Hu (D)*ab
}

In the proposed study, an efficient method for a carbon dot@ $\beta$-cyclodextrin (C-dot@ $\beta$-CD)-based fluorescent probe was developed for the analyses of catechol (CC) and hydroquinone (HQ) at trace levels in water samples. The properties of $C$ - $\operatorname{dot} @ \beta-C D$ nanocomposites were characterized by Fourier transform infrared spectroscopy (FTIR), transmission electron microscopy (TEM) and X-ray photoelectron spectroscopy (XPS). The sensing behaviors of $C-\operatorname{dot} @ \beta-C D$ toward $C C$ and $H Q$ were investigated by fluorescence spectroscopy. Based on the host-guest chemistry between $C-\operatorname{dot} @ \beta-C D$ and phenolic compounds, which can quench C-dot@ $\beta-C D$ fluorescence, the prepared $C$ - $\operatorname{dot} @ \beta-C D$ nanocomposites could be used for the sensitive and selective detection of $\mathrm{CC}$ or $\mathrm{HQ}$ across a wide linear range $(0.1$ to 10 $\mu \mathrm{M})$ with detection limits of 47.9 and $20.2 \mathrm{nM}$, respectively. These results showed that the synthesized $C-\operatorname{dot} @ \beta-C D$ nanocomposite exhibited strong fluorescence and high degree of water solubility and thus, it is suitable for use as a nanoprobe for detecting $\mathrm{CC}$ or $\mathrm{HQ}$ in real water samples.

\section{Introduction}

Catechol (1,2-dihydroxybenzene, CC) and hydroquinone (1,4dihydroxybenzene, HQ) are two positional isomers of phenolic compounds. They are usually found in aquatic environments owing to their widespread use in photography chemicals, secondary coloring materials, medicines, pesticides, flavoring compounds, and cosmetics. ${ }^{\mathbf{1 , 2}}$ However, they are highly toxic to the environment and humans even at very low concentrations. ${ }^{3}$ The United States Environmental Protection Agency and the European Union have found them to be harmful to the environment owing to their biohazard status and low degradability in ecological environments. ${ }^{4,5}$ Various analytical methods including electrochemical methods $s^{6,7}$, spectrophotometry, ${ }^{8}$ chemiluminescence, ${ }^{9}$ capillary electrochromatography, ${ }^{10}$ flowinjection analysis, ${ }^{11}$ high-performance liquid chromatography, ${ }^{12}$ and gas chromatography/mass spectrometry ${ }^{\mathbf{1 3}}$ have been established for their determination. However, these methods are cost- and time-intensive options for detecting CC and HQ.

\footnotetext{
${ }^{a}$ Department of Applied Science, National Taitung University, Taitung, 95002, Taiwan. E-mail: cchu@nttu.edu.tw

${ }^{b}$ Agriculture Products Inspection Center, National Taitung University, Taitung, 95002, Taiwan

${ }^{c}$ Department of Molecular Biology and Human Genetics, Tzu Chi University, Hualien 97004, Taiwan

$\uparrow$ Electronic supplementary information (ESI) available. See DOI: $10.1039 / \mathrm{c} 8 \mathrm{ra} 02813 \mathrm{c}$
}

Recently, numerous nanosensors or nanoprobes have been developed for the determination of organic molecules or metal ions. For example, both $\mathrm{TiO}_{2} \mathrm{NPs}^{14}$ and 4-carboxyphenylboronic acid-functionalized C-dots (CPBA-C-dots) ${ }^{15}$ were used to detect catechol using the fluorescence quenching method. Graphene quantum dots (GQDs) based on a peroxidase-mimicking catalyst were used for the detection of hydroquinone. ${ }^{\mathbf{1 6}}$ Clearly, nanoprobes are more preferable for the detection of CC or HQ, as they have the advantages of low cost, high sensitivity, excellent selectivity simplicity, rapid response and cost-effective equipment.

Cyclodextrin is commonly used as a good selector due to its unique molecular structure, nontoxicity, low cost, bioavailability, ${ }^{17-21}$ and versatile chemical and physical properties. ${ }^{22} \mathrm{~A}$ previous study reported that $\beta$-cyclodextrin-glutathione-capped CdSe/ZnS QDs could be used to detect phenylalanine and tyrosine enantiomers through fluorescence resonance energy transfer (FRET). ${ }^{23}$ Additionally, $\mathrm{Fe}_{3} \mathrm{O}_{4} @ \mathrm{SiO}_{2}$ (FITC)-FA/CMCD NPs with highly uniform and monodispersed multifunctional magnetic properties have been used to study bioimaging, celltargeting and drug delivery. ${ }^{24}$ Gold nanoparticle-doped $\mathrm{Pb}$ (II)$\beta$-cyclodextrin (Pb- $\beta$-CD) metal-organic based on electrochemiluminescence (ECL) resonance energy transfer (RET) system was developed for the determination of insulin. ${ }^{25}$

As nanomaterials, C-dots have become popular green material due to their photostability, high degrees of water solubility and plasticity, low toxicity, and good biocompatibility. ${ }^{26,27}$ Because of these attractive merits, C-dots have been widely used in bioimaging, ${ }^{28,29}$ optoelectronic devices, drug release, and 
fluorescence sensors. ${ }^{\mathbf{3 0 - 3 2}}$ The carbon dots synthesized with terbium(III) nitrate pentahydrate and citric acid have been used to detect trinitrotoluene, ${ }^{33}$ and a new fluorescent probe for $\mathrm{Cu}^{2+}$ detection based on the quenching of the fluorescence of C-dotBSA-lysozyme has been designed. ${ }^{34}$ Moreover, applications of Cdots in the fluorescent sensing of cations, anions, and organic compounds have also been widely reported. Therefore, C-dots can be considered as good candidates for developing rapid and sensitive sensors.

Herein, we describe the development of C-dot@ $\beta$-cyclodextrin $(\beta-\mathrm{CD})$ for the detection of CC and HQ through the hostguest recognition of $\beta$-CD and fluorescence quenching of the $\mathrm{C}$ dots. Based on the host-guest chemistry, the analytes can enter $\beta$-CD cavities to form stable host-guest complexes, thus resulting in C-dot@ $\beta$-CD fluorescence quenching. Our results show that the fluorescent response of this nanoprobe toward CC and HQ is highly sensitive and selective. To the best of our knowledge, few reports have focused on the use of hydrothermal C-dots through the fluorescence method for the detection of CC and HQ.

\section{Experimental}

\section{Materials}

Hydroquinone (1,4-dihydroxybenzene), catechol (1,2-dihydroxybenzene), sodium hydroxide $(\mathrm{NaOH})$, hydrogen peroxide solution $\left(\mathrm{H}_{2} \mathrm{O}_{2}\right)$, methanol $(\mathrm{MeOH})$ and metal ions were obtained from Sigma-Aldrich (St. Louis, MO, USA). $\beta$-Cyclodextrin $(\beta-C D)$ and Rhodamine $\mathrm{B}$ were purchased from TCI (Tokyo Chemical Industry). $p$-Toluenesulfonyl chloride (TsCl) was obtained from ACROS Organics. Acetonitrile (ACN) was purchased from Merck (Darmstadt, Germany). All chemicals were of analytical grade and used without further purification. Ultrapure water was obtained from the Milli-Q ultrapure system. The lake water sample was obtained from a lake on the campus of National Taitung University.

\section{Instrumentation}

UV-vis absorption spectra were obtained using a Lambda EZ210 UV-vis spectrophotometer (Perkin Elmer, USA). Fluorescence spectra were obtained using an F-7000 Fluorescence Spectrophotometer (Hitachi, Japan). The excitation and emission slits were both maintained at $5.0 \mathrm{~nm}$ and $5.0 \mathrm{~nm}$. Versatile disc fluorescence/absorption spectra were recorded on Infinite 200 PRO (Tecan, USA). The morphology and mean diameter of Cdot@ $\beta$-CD were obtained using a transmission electron microscope (TEM, JEM-2100, Hitachi, Japan). X-ray photoelectron spectroscopy (XPS) was conducted using an X-ray photoelectron spectroscope (K-Alpha, Thermo, USA). Cyclic voltammetry was carried out on the CHI624A electrochemical system (Chenhua Instrument, USA). Cyclic voltammograms were measured using an electrochemical workstation (Chenhua Instrument CHI624A, USA) with a conventional three-electrode system including a glassy carbon electrode as the working electrode. $\mathrm{Ag} / \mathrm{AgCl}$ and platinum wire were used as the reference electrode and counter electrode, respectively. ${ }^{35}$

\section{Synthesis of C-dot@ $\beta$-CD}

We developed a strategy according to the previously reported method with minor modifications to obtain the amine group on the carbon dot surface. ${ }^{36}$ Carbon dots were obtained via the hydrothermal method. In detail, $0.72 \mathrm{~g}$ of citric acid was dissolved in a mixed solution containing $1.2 \mathrm{~mL}$ of ethylenediamine and $15 \mathrm{~mL}$ ultra-pure water to form a clear solution. The solution was heated for $8 \mathrm{~h}$ at $240{ }^{\circ} \mathrm{C}$ in a polytetrafluoroethylene autoclave and cooled to room temperature. Then, the solution was transferred to a dialysis bag (3500 Da) and kept for over $24 \mathrm{~h}$ to obtain the C-dot solution.

According to the previously reported procedure, ${ }^{37}$ a solution of TsCl $\left(2.9 \mathrm{~g}, 0.015 \mathrm{~mol} \mathrm{~L}^{-1}\right)$ in acetonitrile $(11 \mathrm{~mL})$ was added dropwise to a solution of $\beta$-CD $(17.22 \mathrm{~g}, 0.015 \mathrm{~mol})$ in $1 \% \mathrm{NaOH}$ aqueous solution $(200 \mathrm{~mL})$, and the mixture was gently stirred; a large quantity of precipitates was obtained. Then, the solution was continuously stirred for $2 \mathrm{~h}$ at room temperature and filtered to obtain a white precipitate. The filtrate was acidified to $\mathrm{pH} 2-3$ with $1.0 \mathrm{~mol} \mathrm{~L}^{-1} \mathrm{HCl}$, and it was kept overnight at $4{ }^{\circ} \mathrm{C}$. Finally, a white solid of mono-6-OTs- $\beta$-CD was precipitated.

Aqueous solutions of C-dots (7 mg mL $\mathrm{mL}^{-1}$ ) and mono-6-OTs- $\beta$ CD (in different volume ratios) were added, and the final volume of the mixture was $10 \mathrm{~mL}$. The $\mathrm{pH}$ of the solution was adjusted to 12 with $1.0 \mathrm{~mol} \mathrm{~L}^{-1} \mathrm{NaOH}$. The mixture was aged for $2 \mathrm{~h}$ to form C-dot@ $\beta$-CD. Then, the solution was transferred to a dialysis bag (3500 Da). The dialysis of the solution lasted over $24 \mathrm{~h}$ and finally, C-dot@ $\beta$-CD solution was obtained $(2.4 \mathrm{mg}$ $\left.\mathrm{mL}^{-1}\right)$.

\section{Determination of hydroquinone and catechol}

To investigate the sensitivity towards hydroquinone and catechol, $200 \mu \mathrm{L}$ hydroquinone or catechol, $200 \mu \mathrm{L}$ C-dot@ $\beta$-CD, and $1400 \mu \mathrm{L} \mathrm{H}_{2} \mathrm{O}$ were placed in cuvettes. Afterwards, the mixtures were incubated for $30 \mathrm{~min}$ at room temperature. The solution was then thoroughly mixed, and the fluorescence intensity was quantified.

The water sample was centrifuged at $12000 \mathrm{rpm}$ for $30 \mathrm{~min}$ and filtered through $0.22 \mu \mathrm{m}$ membranes. Typically, $200 \mu \mathrm{L}$ hydroquinone or catechol, $200 \mu \mathrm{L}$ water sample, $200 \mu \mathrm{L} \mathrm{C}$ dot@ $\beta$-CD, and $1200 \mu \mathrm{L} \mathrm{H}_{2} \mathrm{O}$ were placed in cuvettes. Afterwards, the mixtures were incubated for $30 \mathrm{~min}$ at room temperature. Their fluorescence spectra were recorded in the 200-900 nm emission wavelength range and at the excitation wavelength of $350 \mathrm{~nm}$.

\section{Cell viability assay}

Cell viability was determined by an MTT cell proliferation/ viability assay. Human cervical cancer cells (HeLa) were cultured in a 96-well plate in the DMEM medium supplemented with $10 \%$ fetal bovine serum (Hyclone; Logan, UT, USA) at $37^{\circ} \mathrm{C}$ for 16 hours. After 16 hour incubation to allow cell attachment, the cells were treated with various concentrations of C-dot@ $\beta$ $\mathrm{CD}\left(1.4,0.7,0.47\right.$, and $\left.0.35 \mathrm{mg} \mathrm{mL}^{-1}\right)$ and incubated at $37{ }^{\circ} \mathrm{C}$ and then, they were harvested at different time points. The test solutions were removed and replaced with culture medium 


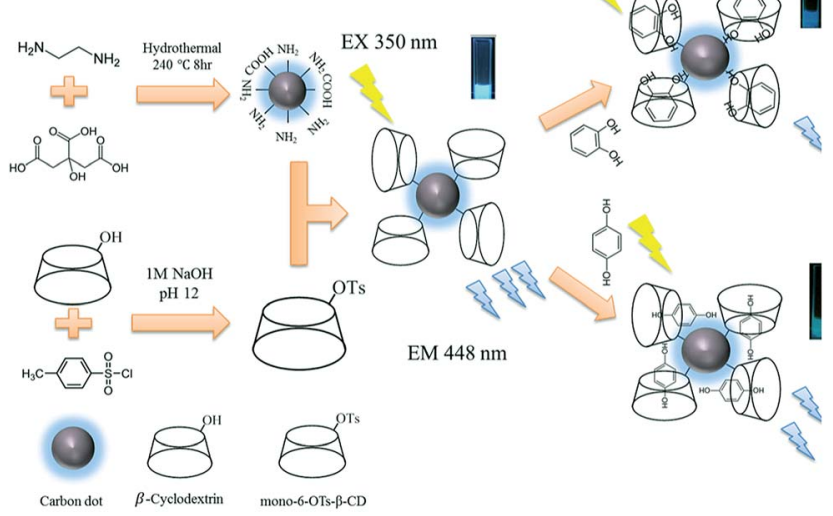

Scheme 1 Schematic representation of the fabrication of C-dot@ $\beta$ $C D$ and illustration of the proposed nanosensor.

containing $5 \mathrm{mg} \mathrm{mL}{ }^{-1}$ of MTT (thiazolyl blue formazan, Sigma, Taiwan) for an additional 4 hours. The supernatant was aspirated, and $200 \mu \mathrm{L}$ of DMSO was added to a well to dissolve the precipitate; optical density (OD) values were then measured using an ELISA reader (Sunrise, Tecan, Switzerland) at a wavelength of $570 \mathrm{~nm}$. Absorbance values were used to calculate the $\%$ viability of the cells relative to that of the control.

\section{Results and discussion}

\section{Synthesis and characterization of the C-dot@ $\beta-C D$ nanocomposites}

As shown in Scheme 1, C-dots were synthesized using citric acid and ethylenediamine. $\beta$-CD was first derivatized with TsCl to form mono-6-OTs- $\beta$-CD. Then, it was used to react with the Cdots to synthesize C-dot@ $\beta$-CDs. C-dot@ $\beta$-CDs were synthesized with mono-6-OTs- $\beta$-CD $(15 \mathrm{mM})$ and C-dots $\left(7 \mathrm{mg} \mathrm{mL}^{-1}\right)$ at various volumetric ratios: $3: 1,4: 1,6: 1,9: 1$ and $12: 1$. Fig. S1† shows the fluorescence spectra of these C-dot@ $\beta$-CDs. The highest fluorescence intensity was observed at $4: 1$ volumetric ratio of mono-6-OTs- $\beta$-CD to C-dot. Fig. S2 $\uparrow$ depicts the fluorescence spectra of C-dot@ $\beta$-CDs based on different incubation times $(2,4,6$ and $8 \mathrm{~h})$ under the same experimental conditions. Our results indicated that after 2 hour incubation, the sample showed the strongest fluorescence intensity at $448 \mathrm{~nm}$; this was likely due to the reaction between mesylate ester groups of $\beta-\mathrm{CD}$ and amine groups of C-dots under these optimized experimental conditions and consequently, the synthesized C-dot@ $\beta$-CD had the highest fluorescence intensity.

The size of the synthesized C-dot@ $\beta-C D$ was characterized with transmission electron microscopy (TEM), as shown in Fig. 1A. The prepared C-dot@ $\beta$-CDs were nearly uniform in size $(\sim 1.97 \mathrm{~nm})$, with narrow size distribution $(\geq 10 \mathrm{~nm})$ and spherical morphology. The properties of C-dot@ $\beta$-CD were further
(A)

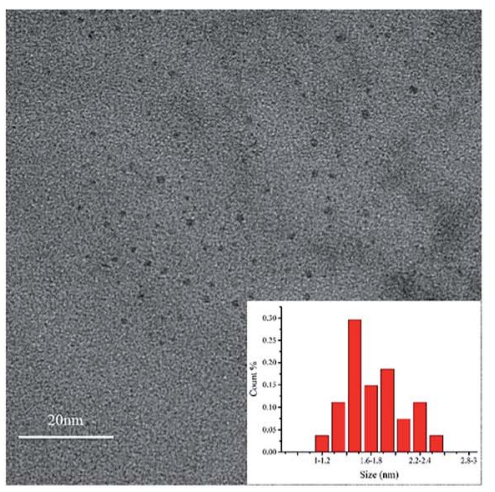

(C)

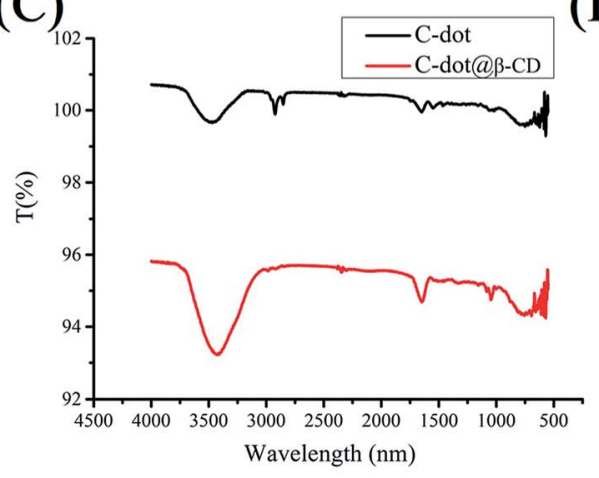

(B)

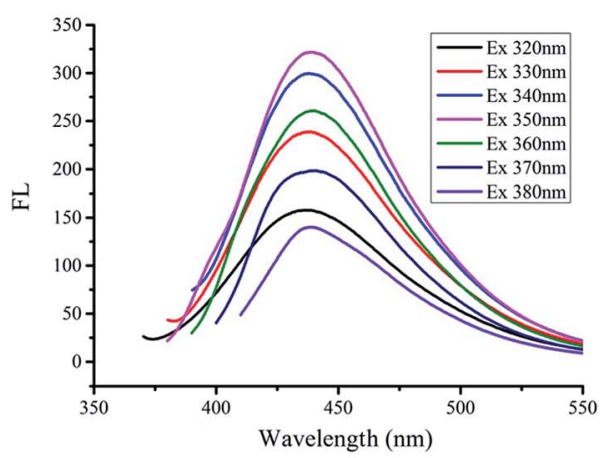

(D)

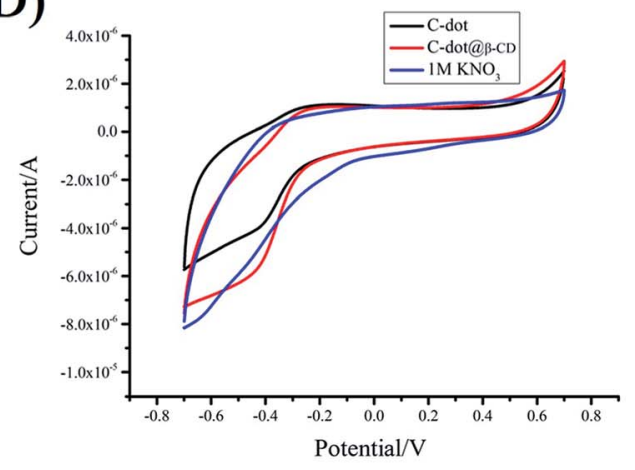

Fig. 1 (A) TEM image of C-dota $\beta$-CD. (B) The excitation-dependent behaviors of C-dot@ $\beta$-CD. (C) FTIR spectra of $C$-dot (black) and C-dota $\beta$ $\mathrm{CD}$ (red). (D) Cyclic voltammograms of (black) C-dot, (red) C-dot@ $\beta-\mathrm{CD}$ and (blue) $1 \mathrm{M} \mathrm{KNO}_{3}$, potential range of $-0.8-0.8 \mathrm{~V}$ versus Ag/AgCl (potential scan rate, $50 \mathrm{mV} \mathrm{s}^{-1}$ ). 
(A)

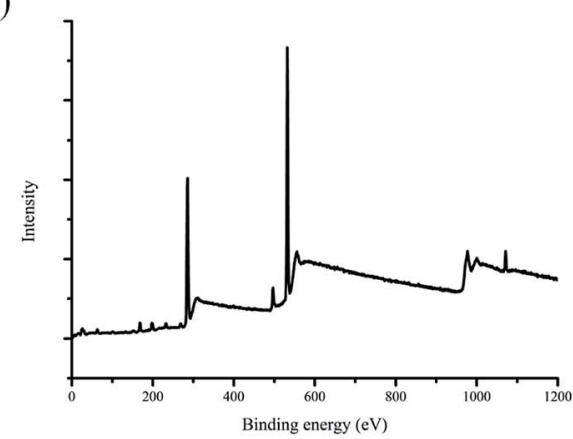

(B)

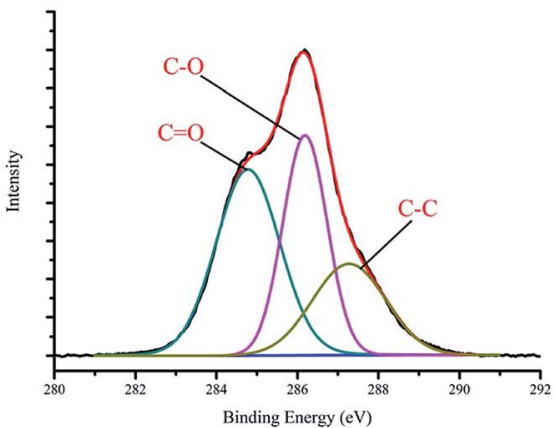

(C)

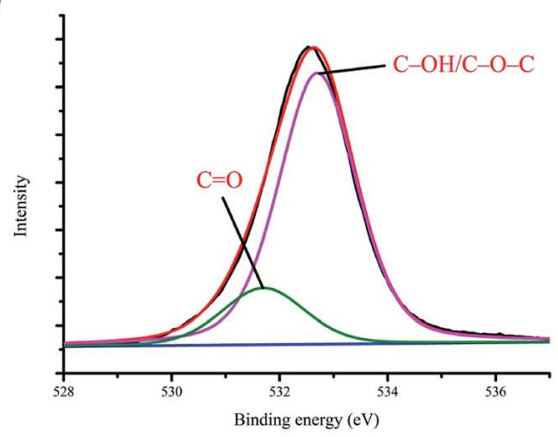

Fig. 2 (A) XPS analysis of $C$ - $\operatorname{dot}(\beta-C D$; high resolution plots of (B) $C 1 \mathrm{~s},(C) \bigcirc 1 \mathrm{~s}$.

characterized using fluorescence spectroscopy. Fig. 1B exhibits the presence of similar excitation-dependent photoluminescence behaviors. This excitation-dependent photoluminescence behavior has been extensively reported for fluorescent carbonbased nanomaterials, which possibly results from the optical selection of C-dots having different sizes and surface defects of Cdots. $^{38}$ As shown in Fig. 1C, the obtained C-dots exhibited a characteristic transmittance band for $\mathrm{O}-\mathrm{H}$ stretching vibrations at $3480 \mathrm{~cm}^{-1}$, and the peak near $1551 \mathrm{~cm}^{-1}$ was attributed to the bending of N-H bonds. ${ }^{39,40}$ Additionally, the peaks at $2925 \mathrm{~cm}^{-1}$ and $2852 \mathrm{~cm}^{-1}$ were assigned to the stretching of $\mathrm{C}-\mathrm{H}$ bonds, and the peak at $1648 \mathrm{~cm}^{-1}$ represented the vibrational transmittance band of $\mathrm{C}-\mathrm{O}$ bonds. ${ }^{\mathbf{4 1 , 4 2}}$ The Fourier transform infrared (FTIR) spectra of C-dot@ $\beta$-CD also showed transmittance bands at $3430 \mathrm{~cm}^{-1}$ and $1648 \mathrm{~cm}^{-1}$. The nucleophilic substitution reaction proceeded easily because mesylate ester is a good leaving group, and this resulted in a weak amine-group peak in the Cdot@ $\beta$-CD FTIR spectra. These results confirmed that the C-dots were successfully functionalized by $\beta-\mathrm{CD}$.

To investigate the electrochemical behaviors of C-dots and Cdot@ $\beta$-CDs, we compared their cyclic voltammograms (Fig. 1D), and we found no clear redox peaks in the potential range of $-0.8 \mathrm{~V}$ to $0.8 \mathrm{~V}$. The results suggested that both of these C-dots were chemically stable. The FTIR assignments were further verified by XPS analysis. Fig. 2 reveals that C-dot@ $\beta$-CD mainly consisted of carbon and oxygen with a peak at about $285 \mathrm{eV}$ for $\mathrm{C} 1 \mathrm{~s}$ and a peak at about $532 \mathrm{eV}$ for $\mathrm{O} 1 \mathrm{~s} .{ }^{43}$ The $\mathrm{C} 1 \mathrm{~s}$ spectra (Fig. 2B) showed three peaks at $284.6 \mathrm{eV}, 285.9 \mathrm{eV}$ and $287.9 \mathrm{eV}$, which were ascribed to $\mathrm{C}-$ $\mathrm{C}, \mathrm{C}-\mathrm{O}$ and $\mathrm{C}=\mathrm{O}$ bands, respectively, ${ }^{44}$ whereas the two fitted peaks at $531.7 \mathrm{eV}$ and $532.7 \mathrm{eV}$ in the $\mathrm{O} 1 \mathrm{~s}$ spectrum (Fig. 2C) were assigned to $\mathrm{C}=\mathrm{O}$ and $\mathrm{C}-\mathrm{OH} / \mathrm{C}-\mathrm{O}-\mathrm{C}$ groups, respectively. ${ }^{45}$
The remarkable optical properties of the fabricated Cdot@ $\beta$-CD were confirmed by UV-vis absorption and fluorescence spectra (Fig. 3). We observed a broad UV-vis absorption band $(220 \mathrm{~nm})$, which was ascribed to the $\mathrm{n}-\pi *$ transition of $\mathrm{C}$ dot@ $\beta$-CD. However, the nanocomposites showed fluorescence responses, indicating maximum excitation and emission spectra at $350 \mathrm{~nm}$ and $448 \mathrm{~nm}$, respectively. ${ }^{26}$ We investigated the effects of $\mathrm{pH}$ on the fluorescence intensity of C-dot@ $\beta$-CDs because $\mathrm{pH}$ is often an important factor affecting the fluorescence intensity of fluorescent probes. As shown in Fig. S3A, $\uparrow$ the fluorescence intensity decreased slightly at $\mathrm{pH} 12$, whereas no significant change was observed in the $\mathrm{pH}$ range from 5 to 11 . This result might be explained by the protonation and deprotonation of C-dot@ $\beta$-CD. Besides, stability is also an important

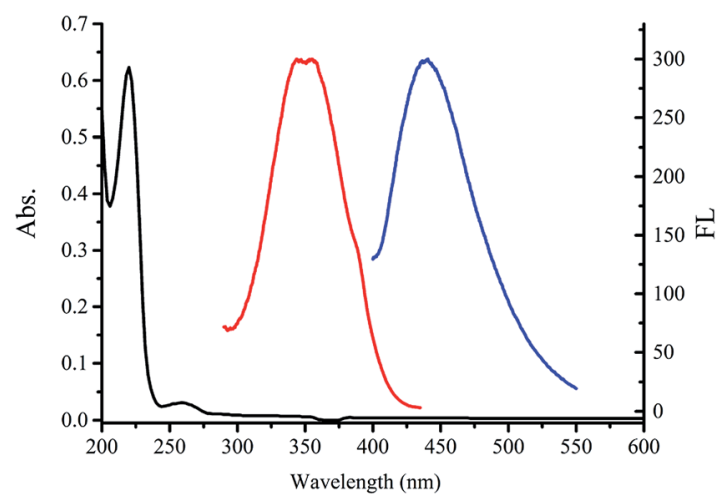

Fig. 3 UV-vis absorption (black line), fluorescence excitation (red line) and emission (blue line) spectra of $C-\operatorname{dot} a \beta-C D$ in aqueous solution (inset: photographs of $C$ - $\operatorname{dot}(a-C D$ solution under visible light and under UV light). 


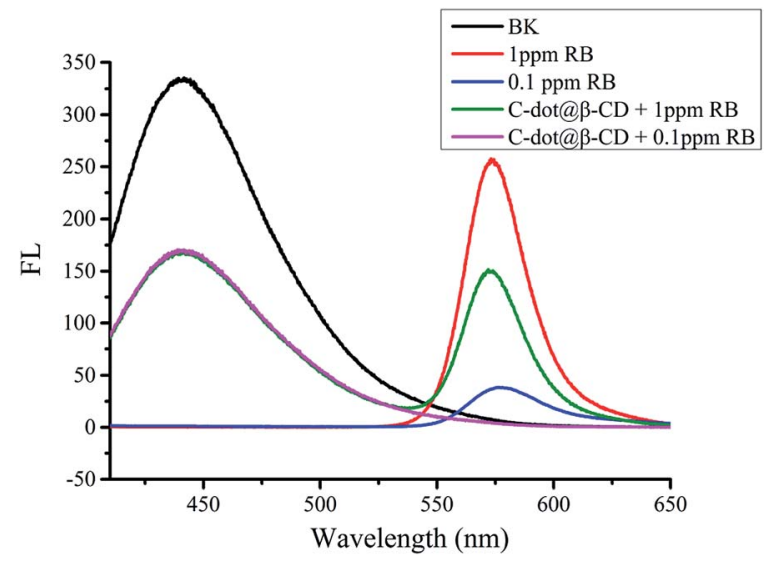

Fig. 4 Fluorescence spectra responses of $C$ - $\operatorname{dot} @ \beta-C D$ (black), 1 ppm RB (red), 0.1 ppm RB (blue), C-dot $a-C D+1$ ppm RB (green), C$\operatorname{dot} a-C D+0.1$ ppm RB (pink).

factor for a nanoprobe. We further investigated the salt tolerance and light stability of C-dot@ $\beta-C D$ through fluorescence intensity. Fig. $\mathrm{S} 3 \mathrm{~B} \uparrow$ shows that the fluorescence intensity of $\mathrm{C}$ dot@ $\beta$-CD remained almost constant at different sodium chloride concentrations up to $1 \mathrm{M}$. As shown in Fig. S3C, $\dagger$ the fluorescence intensity was also unaffected after irradiation (EX $350 \mathrm{~nm}$ ) for $1 \mathrm{~h}$. We also investigated C-dot@ $\beta$-CD fluorescence intensity (Fig. S3D $\dagger$ ) in the presence of various organic solvents such as acetone, acetonitrile (ACN), isopropanol (IPA), ethanol $(\mathrm{EtOH})$ and ethylene glycol (EG). It was found that the fluorescence intensity changed with polarity and solubility of these solvents. However, C-dot@ $\beta$-CD was well-dispersed, and no precipitation was observed in any of the organic solvents. These results showed that C-dot@ $\beta$-CD had excellent salt tolerance, light stability, and good solubility in organic solvents.

\section{Photoinduced electron transfer between C-dot@ $\beta$-CD and Rhodamine B (RB)}

To ensure that $\beta$-cyclodextrin was modified on C-dots, we studied the fluorescence intensity of C-dot@ $\beta-\mathrm{CD}$ in different concentrations of RB. As shown in Fig. 4, there were clear discrepancies between the emissions at 448 nm (from C-dot@ $\beta$ $\mathrm{CD}$ ) and $575 \mathrm{~nm}$ (from RB). Upon addition of $0.1 \mathrm{ppm} \mathrm{RB}$ to the C-dot@ $\beta$-CD solution, the original fluorescence emission (575 $\mathrm{nm}$ ) of RB disappeared. This phenomenon may have been due to the ability of RB to enter the cavity of the $\beta$-CD moiety in the nanoprobe, which was attributed to their specific host-guest recognition. ${ }^{46}$ When 1 ppm $\mathrm{RB}$ was mixed with the C-dot@ $\beta$-CD solution, it was observed that RB fluorescence intensity (green line) was about $58.3 \%$ lower than the original fluorescence intensity (red line) of $1 \mathrm{ppm} \mathrm{RB}$. We conjectured that few molecules of RB entered the cavity of $\beta-C D$, which caused the difference in fluorescence intensities at the same concentration. This phenomenon implied that RB may have interacted with the C-dot@ $\beta$-CD probe, which affected its optical property. We believe that our C-dot@ $\beta$-CD can be developed as a nanoprobe for sensing organic compounds through host-guest recognition.

\section{Fluorescence detection of CC and HQ using C-dot@ $\beta-C D$}

In our previous study, $\beta$-CD functionalization with $\mathrm{C}$-dots created a hydrophobic environment on the C-dot surface. Because of the unique molecular structures of CC and HQ, these phenolic compounds can enter the cavity of C-dot@ $\beta$-CD. This process reduces the distance between these phenolic compounds and the surface of the C-dots. Here, we observed almost no overlap between the fluorescence spectra of C-dot@ $\beta$ $\mathrm{CD}$ and the spectra of $\mathrm{CC}$ and HQ, which ruled out inner-filter effects related to fluorescence quenching (Fig. S4†). High quenching efficiency of C-dot@ $\beta$-CD was observed in the presence of micromolar concentrations of CC or HQ, which suggested that there could be photoinduced electron transfer (PET) between C-dot@ $\beta$-CD and these two analytes. ${ }^{46}$ Time-resolved fluorescence decay curves for C-dot@ $\beta$-CD in the absence and presence of CC and HQ were further analyzed, as shown in Fig. S5. $\uparrow$ As illustrated in Table $S 1, \dagger$ a change in the fluorescence decay time was observed from 9.96 ns (C-dot@ $\beta$-CD alone) to
(A)

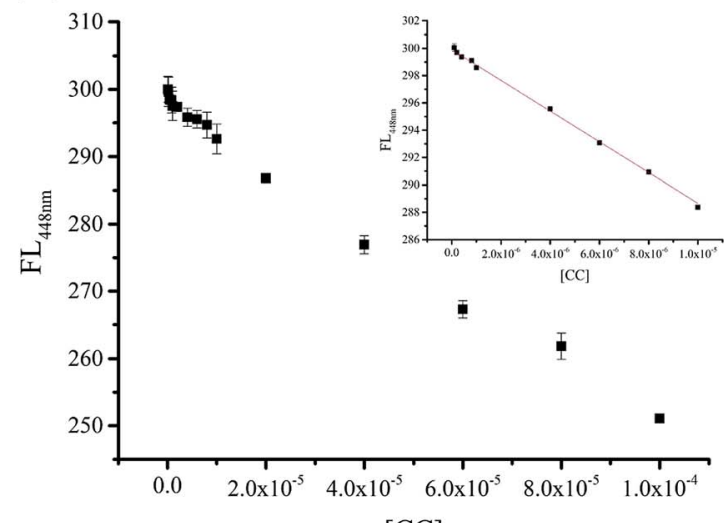

(B)

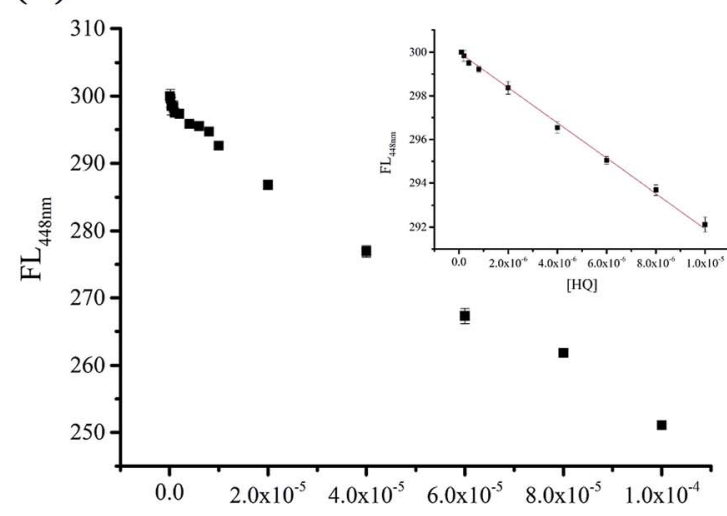

[HQ]

Fig. 5 Fluorescence spectra of C-dota $\beta-C D$ upon the addition of different concentrations of (A) catechol in the range of $10^{-4}$ to $10^{-7} \mathrm{M}$ and $(B)$ hydroquinone in the range of $10^{-4}$ to $10^{-8} \mathrm{M}$. Inset: the plots of fluorescence intensity at $448 \mathrm{~nm}$ at different concentrations of catechol and hydroquinone. 
(A)

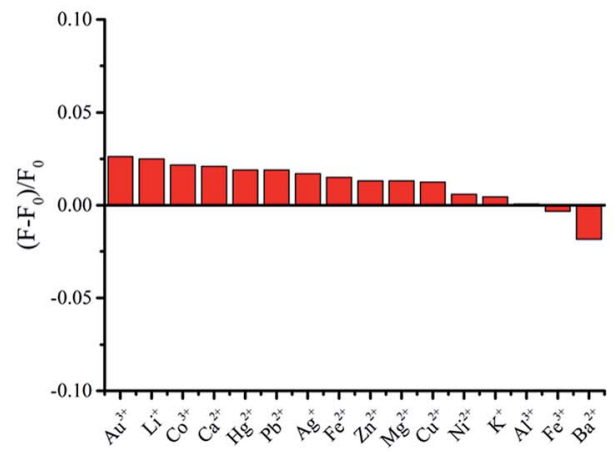

(B)

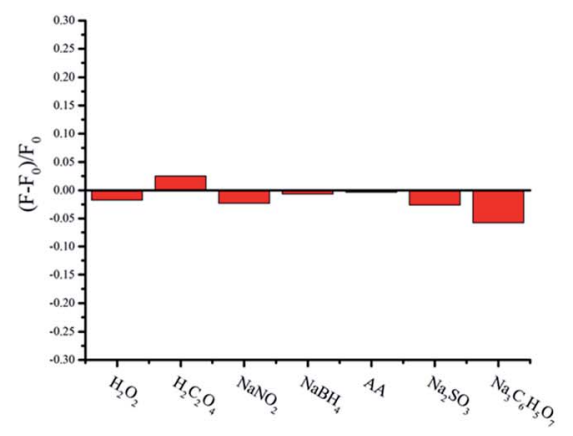

Fig. 6 (A) Comparison of the fluorescence intensities of $C$-dot@ $\beta-C D$ after the addition of different metal ions (the concentration of metal ions was $10 \mu \mathrm{M}$ ). (B) Fluorescence response of $\mathrm{C}$-dota $\beta-C D$ in the presence of different oxidizing/reducing agents (the concentration of each type of oxidizing/reducing agent was $0.1 \mathrm{mM}$ ).

$4.30 \mathrm{~ns}$ or $3.85 \mathrm{~ns}$ for C-dot@ $\beta$-CD in the presence of CC or HQ, respectively. We believe that PET probably caused the fluorescence quenching, where C-dot@ $\beta$-CD and the phenolic compounds served as electron donor and electron acceptors, respectively. ${ }^{47}$

As the concentrations of $\mathrm{CC}$ and $\mathrm{HQ}$ increased, the fluorescence intensity of C-dot@ $\beta$-CDs gradually decreased. For CCand HQ-detection studies, we used different concentrations of $\mathrm{CC}$ and $\mathrm{HQ}$ in the range of $\sim 10^{-4} \mathrm{M}$ to $10^{-8} \mathrm{M}$; Fig. 5 shows the fluorescence spectra corresponding to C-dot@ $\beta$-CDs at different $\mathrm{CC}$ and $\mathrm{HQ}$ concentrations. A linear relationship was observed between the fluorescence intensity and CC concentration [0.1$10 \mu \mathrm{M}\left(R^{2}=0.997\right)$ with a limit of detection (LOD, S/N > 3) of $20.2 \mathrm{nM}]$ as well as HQ concentration $\left[0.1-10 \mu \mathrm{M}\left(R^{2}=0.996\right)\right.$, with LOD of $47.9 \mathrm{nM}]$. These results improved upon those previously reported using a common spectrophotometric method (HQ: $1.45 \mathrm{mM}){ }^{48}$

An interference study of the novel analytical method was carried out with the addition of different, potentially interfering substances, which could be present in actual samples. Therefore, we added other common ions such as $\mathrm{Au}^{3+}, \mathrm{Li}^{+}, \mathrm{Co}^{3+}, \mathrm{Ca}^{2+}$, $\mathrm{Hg}^{2+}, \mathrm{Pd}^{2+}, \mathrm{Ag}^{+}, \mathrm{Fe}^{2+}, \mathrm{Zn}^{2+}, \mathrm{Mg}^{2+}, \mathrm{Cu}^{2+}, \mathrm{Ni}^{2+}, \mathrm{K}^{+}, \mathrm{Al}^{3+}, \mathrm{Fe}^{3+}$ and
$\mathrm{Ba}^{2+}$ in the C-dot@ $\beta$-CD system (Fig. 6A). On the other hand, with the addition of common oxidants and reductants such as $\mathrm{H}_{2} \mathrm{O}_{2}, \mathrm{H}_{2} \mathrm{C}_{2} \mathrm{O}_{4}, \mathrm{NaNO}_{2}, \mathrm{NaBH}_{4}, \mathrm{AA}, \mathrm{Na}_{2} \mathrm{SO}_{3}$ and $\mathrm{Na}_{3} \mathrm{C}_{6} \mathrm{H}_{5} \mathrm{O}_{7}$, there was almost no change in the fluorescence intensity of the C-dot@ß-CD system (Fig. 6B). The results suggested that there were only small changes in the fluorescence of the C-dot@ $\beta-\mathrm{CD}$ system in the presence of metal ions and oxidizing/reducing agents. A comparison of the limit of detection and linear range of this method with those of other methods for detecting phenolic compounds is shown in Table 1. It should be noted that our C-dot@ $\beta$-CD sensor for CC and HQ detection had lower LOD and better linear range than those previously reported with other methods. ${ }^{49-57}$

\section{Cell viability assays}

To understand the viability of our nanoprobe, we studied the effects of various doses of nanoparticles in cells. The HaCaT cells were exposed to four different concentrations of C-dot@ßCD solutions from 1.4 to $3.5 \mathrm{mg} \mathrm{mL}^{-1}$, and $\mathrm{ddH}_{2} \mathrm{O}$ was used as control. At each time point, the cells were harvested for MTT assay. At a concentration of $0.7 \mathrm{mg} \mathrm{mL} \mathrm{mL}^{-1}$, it was found that the cell viability was not affected. The cell viability was still more

Table 1 Comparison with other sensors for determination of hydroquinone and catechol ${ }^{a}$

\begin{tabular}{|c|c|c|c|c|c|c|}
\hline Sensors & Method & HQ & $\mathrm{CC}$ & HQ & $\mathrm{CC}$ & Reference \\
\hline $\mathrm{Pt}-\mathrm{MnO}_{2} / \mathrm{GCE}$ & Electrochemical & $3-481$ & $15-447$ & - & - & 49 \\
\hline PASA/MWNTs/GCE & Electrochemical & $8-391$ & $5.5-540$ & 2.60 & 1.80 & 50 \\
\hline $\mathrm{CNF} / \mathrm{GCE}$ & Electrochemical & $6-200$ & $2-200$ & 0.25 & 0.1 & 51 \\
\hline MWCNT-PMG/GCE & Electrochemical & $10-480$ & $30-1190$ & 1.60 & 5.80 & 54 \\
\hline MWCNT/PMT & Electrochemical & $0.5-200$ & $0.5-150$ & 0.05 & 0.05 & 55 \\
\hline CNF-AuNPs & Electrochemical & $9-500$ & $5-350$ & 0.86 & 0.36 & 56 \\
\hline Au@Pd/rGO & Electrochemical & $0.01-400$ & $0.1-400$ & 0.01 & 0.1 & 57 \\
\hline C-dot@ $\beta-C D$ & Fluorescence & $0.1-10$ & $0.1-100$ & 0.020 & 0.048 & This work \\
\hline
\end{tabular}

${ }^{a}$ RGO: reduced graphene oxide, CNF: carbon nano-fragment, PASA: poly-amidosulfonic acid, PIL: polymeric ionic liquid, PDA: polydopamine, MWCNT: multi-walled carbon nanotube, PMG: poly-malachite green, PMT: poly(3-methylthiophene). 
Table 2 Determination of catechol and hydroquinone in water sample $(n=3)$

\begin{tabular}{llllll}
\hline \multirow{2}{*}{ Analyte } & Sample & $\begin{array}{l}\text { Added } \\
(\mu \mathrm{M})\end{array}$ & $\begin{array}{l}\text { Found } \\
(\mu \mathrm{M})\end{array}$ & $\begin{array}{l}\text { Recovery } \\
(\%)\end{array}$ & $\begin{array}{l}\text { RSD } \\
(\%)\end{array}$ \\
\hline \multirow{2}{*}{ Catechol } & Lake & 10 & 10.30 & 103.0 & 2.64 \\
& water & 20 & 20.42 & 102.1 & 3.05 \\
& & 50 & 48.85 & 97.7 & 2.51 \\
& Tap water & 10 & 10.05 & 100.5 & 2.08 \\
& & 20 & 20.04 & 100.4 & 3.00 \\
& & 50 & 50.04 & 100.4 & 1.52 \\
& & 10 & 10.05 & 100.5 & 2.51 \\
& Lake & 20 & 19.4 & 97.4 & 2.00 \\
& water & 50 & 52.8 & 105.6 & 2.64 \\
& Tap water & 10 & 10.6 & 106.7 & 4.04 \\
& & 20 & 20.0 & 100.0 & 1.73 \\
& & 50 & 50.5 & 101.0 & 0.57
\end{tabular}

than $80 \%$ at a high concentration of $1.4 \mathrm{mg} \mathrm{mL}^{-1}$. Our results showed that the nanoparticles affected the HeLa cells only to a slight extent.

\section{Application of C-dot@ $\beta$-CD determination of catechol and hydroquinone in real water samples}

To investigate the efficacy of this method, it was applied for the detection of phenolic compounds in tap water and lake water samples. All real samples were spiked with CC or HQ at concentrations of $10 \mu \mathrm{M}, 20 \mu \mathrm{M}$, and $50 \mu \mathrm{M}$, and they were centrifuged at $12000 \mathrm{rpm}$ for $30 \mathrm{~min}$, as described in the Experimental methods section. Our results showed recovery of $97.4 \%$ to $106.7 \%$, with a relative standard deviation of $<4.04 \%$ (Table 2). These results showed that this probe system which used fluorescence as a signal was suitable for the rapid determination (30 $\mathrm{min}$ ) of phenolic compounds in environmental water samples.

\section{Conclusion}

In summary, a highly sensitive and selective method for the detection of catechol and hydroquinone was developed with $\beta$ CD-modified C-dots. The water-soluble C-dot@ $\beta$-CD nanocomposites were stable, uniform in size, and well-dispersed in solutions, and they showed excellent optical properties. Due to the synergistic effect of the hydrothermal C-dots (high degree of water solubility and excellent optical properties) and $\beta-\mathrm{CD}$ (enables host-guest recognition), the C-dot@ $\beta-C D$ nanocomposites displayed excellent analytical performances for the selective and sensitive determination of CC and HQ. Importantly, organic dyes and other environmentally problematic compounds were not required in our system. Additionally, this novel method is environmentally friendly, and it exhibits good biocompatibility. Furthermore, our results suggested that Cdot@ $\beta$-CDs can also be potentially useful for cell imaging applications and recognition of chiral molecules.

\section{Conflicts of interest}

There are no conflicts to declare.

\section{Acknowledgements}

This work was supported by the NTTU and Ministry of Science and Technology, Taiwan (MOST106-2113-M-143-003).

\section{Notes and references}

1 M. Blaut, A. Braune, S. Wunderlich, P. Sauer, H. Schneider and H. Glatt, Food Chem. Toxicol., 2006, 44, 1940-1947.

2 H. Du, J. Ye, J. Zhang, X. Huang and C. Yu, J. Electroanal. Chem., 2011, 650, 209-213.

3 H. Yin, Q. Zhang, Y. Zhou, Q. Ma, T. liu, L. Zhu and S. Ai, Electrochim. Acta, 2011, 56, 2748-2753.

4 Y. Wang, Y. Xiong, J. Qu, J. Qu and S. Li, Sens. Actuators, B, 2016, 223, 501-508.

5 W. Si, W. Lei, Z. Han, Q. Hao, Y. Zhang and M. Xia, Sens. Actuators, B, 2014, 199, 154-160.

6 L. Tang, Y. Zhou, G. Zeng, Z. Li, Y. Liu, Y. Zhang, G. Chen, G. Yang, X. Lei and M. Wu, Analyst, 2013, 138, 3552-3560.

7 Y. Zhang, S. Xiao, J. Xie, Z. Yang, P. Pang and Y. Gao, Sens. Actuators, B, 2014, 204, 102-108.

8 P. Nagaraja, R. A. Vasantha and K. R. Sunitha, Talanta, 2001, 55, 1039-1046.

9 H. Cui, C. He and G. Zhao, J. Chromatogr. A, 1999, 855, 171179.

10 N. Guan, Z. Zeng, Y. Wang, E. Fu and J. Cheng, Anal. Chim. Acta, 2000, 418, 145-151.

11 J. A. Garcia-Mesa and R. Mateos, J. Agric. Food Chem., 2007, 55, 3863-3868.

12 G. Marrubini, E. Calleri, T. Coccini, A. F. Castoldi and L. Manzo, Chromatographia, 2005, 62, 25-31.

13 S. C. Moldoveanu and M. Kiser, J. Chromatogr. A, 2007, 1141, 90-97.

14 H.-P. Wu, T.-L. Cheng and W.-L. Tseng, Langmuir, 2007, 23, 7880-7885.

15 Q. Ye, F. Yan, D. Kong, J. Zhang, X. Zhou, J. Xu and L. Chen, Sens. Actuators, B, 2017, 250, 712-720.

16 Y. He, J. Sun, D. Feng, H. Chen, F. Gao and L. Wang, Biosens. Bioelectron., 2015, 74, 418-422.

17 H. Zhang, P. Dai, L. Huang, Y. Huang, Q. Huang, W. Zhang, C. Wei and S. Hu, Anal. Methods, 2014, 6, 2687-2691.

18 C. Tang, Z. Qian, Y. Qian, Y. Huang, M. Zhao, H. Ao and H. Feng, Sens. Actuators, B, 2017, 245, 282-289.

19 C. Tang, J. Zhou, Z. Qian, Y. Ma, Y. Huang and H. Feng, J. Mater. Chem. B, 2017, 5, 1971-1979.

20 X. Meng, Q. Chang, C. Xue, J. Yang and S. Hu, Chem. Commun., 2017, 53, 3074-3077.

21 Q. Sun, S. Fang, Y. Fang, Z. Qian and H. Feng, Talanta, 2017, 167, 513-519.

22 C. Yang, C. Ke, W. Liang, G. Fukuhara, T. Mori, Y. Liu and Y. Inoue, J. Am. Chem. Soc., 2011, 133, 13786-13789.

23 R. Freeman, T. Finder, L. Bahshi and I. Willner, Nano Lett., 2009, 9, 2073-2076.

24 A. Z. M. Badruddoza, M. T. Rahman, S. Ghosh, M. Z. Hossain, J. Shi, K. Hidajat and M. S. Uddin, Carbohydr. Polym., 2013, 95, 449-457. 
25 H. Ma, X. Li, T. Yan, Y. Li, H. Liu, Y. Zhang, D. Wu, B. Du and Q. Wei, ACS Appl. Mater. Interfaces, 2016, 8, 10121-10127.

26 M. Zheng, Z. Xie, D. Qu, D. Li, P. Du, X. Jing and Z. Sun, ACS Appl. Mater. Interfaces, 2013, 5, 13242-13247.

27 J. Zong, X. Yang, A. Trinchi, S. Hardin, I. Cole, Y. Zhu, C. Li, T. Muster and G. Wei, Biosens. Bioelectron., 2014, 51, 330335.

28 S. Sun, L. Zhang, K. Jiang, A. Wu and H. Lin, Chem. Mater., 2016, 28, 8659-8668.

29 Y. Zhang, W. Liu, S. Ge, M. Yan, S. Wang, J. Yu, N. Li and X. Song, Biosens. Bioelectron., 2013, 41, 684-690.

30 Y. Li, Y. Zhao, H. Cheng, Y. Hu, G. Shi, L. Dai and L. Qu, J. Am. Chem. Soc., 2012, 134, 15-18.

31 L. Zheng, Y. Chi, Y. Dong, J. Lin and B. Wang, J. Am. Chem. Soc., 2009, 131, 4564-4565.

32 T.-R. Kuo, S.-Y. Sung, C.-W. Hsu, C.-J. Chang, T.-C. Chiu and C.-C. Hu, Anal. Bioanal. Chem., 2016, 408, 77-82.

33 B. B. Chen, Z. X. Liu, H. Y. Zou and C. Z. Huang, Analyst, 2016, 141, 2676-2681.

34 J.-M. Liu, L.-p. Lin, X.-X. Wang, S.-Q. Lin, W.-L. Cai, L.-H. Zhang and Z.-Y. Zheng, Analyst, 2012, 137, 2637-2642.

35 H. Peng, Y. Li, C. Jiang, C. Luo, R. Qi, R. Huang, C.-G. Duan and J. Travas-Sejdic, Carbon, 2016, 100, 386-394.

36 S. Zhu, Q. Meng, L. Wang, J. Zhang, Y. Song, H. Jin, K. Zhang, H. Sun, H. Wang and B. Yang, Angew. Chem., 2013, 125, 4045-4049.

37 Y. Wei, H. Li, H. Hao, Y. Chen, C. Dong and G. Wang, Polym. Chem., 2015, 6, 591-598.

38 S. N. Baker and G. A. Baker, Angew. Chem., Int. Ed., 2010, 49, 6726-6744.

39 Q. Chang, K. K. Li, S. L. Hu, Y. G. Dong and J. L. Yang, Mater. Lett., 2016, 175, 44-47.

40 A. Gupta, N. C. Verma, S. Khan and C. K. Nandi, Biosens. Bioelectron., 2016, 81, 465-472.
41 A. Gupta, N. C. Verma, S. Khan, S. Tiwari, A. Chaudhary and C. K. Nandi, Sens. Actuators, B, 2016, 232, 107-114.

42 T. N. J. I. Edison, R. Atchudan, M. G. Sethuraman, J.-J. Shim and Y. R. Lee, J. Photochem. Photobiol., B, 2016, 161, 154-161.

43 K. Li, F.-Y. Su and W.-D. Zhang, Appl. Surf. Sci., 2016, 375, 110-117.

44 S. Hu, Z. Wei, Q. Chang, A. Trinchi and J. Yang, Appl. Surf. Sci., 2016, 378, 402-407.

45 W. Lu, X. Qin, S. Liu, G. Chang, Y. Zhang, Y. Luo, A. M. Asiri, A. O. Al-Youbi and X. Sun, Anal. Chem., 2012, 84, 5351-5357.

46 C. Tang, Z. Qian, Y. Huang, J. Xu, H. Ao, M. Zhao, J. Zhou, J. Chen and H. Feng, Biosens. Bioelectron., 2016, 83, 274-280.

47 M. Luo, Y. Hua, Y. Liang, J. Han, D. Liu, W. Zhao and P. Wang, Biosens. Bioelectron., 2017, 98, 195-201.

48 Y. Ni, Z. Xia and S. Kokot, J. Hazard. Mater., 2011, 192, 722729.

49 B. Unnikrishnan, P.-L. Ru and S.-M. Chen, Sens. Actuators, B, 2012, 169, 235-242.

50 F. Hu, S. Chen, C. Wang, R. Yuan, D. Yuan and C. Wang, Anal. Chim. Acta, 2012, 724, 40-46.

51 C. Zhang, L. Zeng, X. Zhu, C. Yu, X. Zuo, X. Xiao and J. Nan, Anal. Methods, 2013, 5, 2203-2208.

52 X. Feng, W. Gao, S. Zhou, H. Shi, H. Huang and W. Song, Anal. Chim. Acta, 2013, 805, 36-44.

53 L. Zheng, L. Xiong, Y. Li, J. Xu, X. Kang, Z. Zou, S. Yang and J. Xia, Sens. Actuators, B, 2013, 177, 344-349.

54 Y. Umasankar, A. P. Periasamy and S.-M. Chen, Anal. Biochem., 2011, 411, 71-79.

55 H. Zhang, J. Zhao, H. Liu, R. Liu, H. Wang and J. Liu, Microchim. Acta, 2010, 169, 277-282.

56 Z. Huo, Y. Zhou, Q. Liu, X. He, Y. Liang and M. Xu, Microchim. Acta, 2011, 173, 119-125.

57 H. Wang, S. Zhang, S. Li and J. Qu, Anal. Methods, 2018, 10, 1331-1338. 